\title{
Erratum to: Serotonin transporter activity and serotonin concentration in platelets of patients with irritable bowel syndrome: effect of gender
}

\author{
Leonora Franke • Marco Schmidtmann • \\ Andrea Riedl • Ivo van der Voort • Ralf Uebelhack • \\ Hubert Mönnikes
}

Published online: 13 February 2010

(C) Springer 2010

Erratum to: J Gastroenterol

DOI 10.1007/s00535-009-0167-y

The correct name of the third author should be given as Andrea Riedl, not Anne Riedl.

The online version of the original article can be found under doi:10.1007/s00535-009-0167-y.

L. Franke $(\bowtie) \cdot$ R. Uebelhack

Department of Psychiatry and Psychotherapy,

Charité-Universitätsmedizin Berlin,

Campus Charité Mitte (CCM),

Schumannstr. 20-21, 10117 Berlin, Germany

e-mail: leonora.franke@charite.de

M. Schmidtmann · I. van der Voort · H. Mönnikes

Division of Hepatology, Gastroenterology, and Endocrinology,

Department of Medicine, Charité-Universitätsmedizin Berlin,

Campus Virchow-Klinikum, Berlin, Germany
A. Riedl
Department of Psychosomatic Medicine,
Charité-Universitätsmedizin Berlin,
Campus Mitte, Berlin, Germany

M. Schmidtmann · H. Mönnikes

Department of Medicine and Institute of Neurogastroenterology,

Martin Luther Hospital, Academic Teaching Institute

of Charité-Universitätsmedizin, Berlin, Germany 